\title{
Selection and Structuring of Training Multimedia Educational Materials for University Students: Practical Recommendations
}

\section{Irina V. Terentyeva}

Kazan (Volga region) Federal University, Kazan, Russia, m iterenteva49@mail.ru

\section{Natalya B. Pugacheva}

Kazan State University of Architecture and Engineering, Russia,pug4chevanat@yandex.ru

\section{Anastasia O. Luchinina}

Vyatka state University, Kirov, Russia, a8210@ rambler.ru

\section{Timur A. Khalmetov}

Kazan Law Institute of the Ministry of Internal Affairs of the Russian Federation, Kazan, Russia,volk-nk@mail.ru

\section{Niyaz M. Safin}

Kazan Law Institute of the Ministry of Internal Affairs of the Russian Federation, Kazan, Russia,akontan@mail.ru

\section{Alsu N. Shaydullina}

Kazan State University of Architecture and Engineering, Russia, i26-05@yandex.ru

The purpose of the article is to develop practical recommendations on the selection and structuring of educational material for a multimedia and training complex on occupational safety for future civil engineers. 450 people participated in the experimental work: 50 teachers, 400 students of the federal state budgetary educational institution of higher education. A survey with open and close questions was used in the research. Later it was analyzed using the methodology of quantitative research. The significance of the results obtained is that the methods of selection of educational material ensure the formation of competences, skills of research activities, practice-oriented orientation and compliance with students' expectations. The identified criteria (knowledge, activity, competence) contribute to the integration of educational material; the formation of knowledge, skills, abilities, competences to ensure occupational safety.

Keywords: educational material, multimedia educational complex, university students, students' expectations, occupational safety

Citation: Terentyeva, I. V., Pugacheva, N. B., Luchinina, A. O., Khalmetov, T. A., Safin, N. M., \& Shaydullina, A. N. (2019). Selection and Structuring of Training Multimedia Educational Materials for University Students: Practical Recommendations. International Journal of Instruction, 12(3), 759-780. https://doi.org/10.29333/iji.2019.12346a 


\section{INTRODUCTION}

The problem of selecting and structuring educational material for a multimedia learning complex is attracting increasing attention of scientists (Gikas\&Grant, 2013; Aleksic\&Ivanovic, 2016; Chareen, 2018). This allows us to highlight the both the international and local trends. International trends are aimed at optimizing the quality of education (Dorca et al., 2016; Potter, 2018), increasing digital literacy (McDougall et al., 2018; Means, 2018). They mainly include the development of methods for the selection and structuring of educational material multimedia-learning systems necessary for:

1) creating educational software environments and multimedia training courses (Brilingaite et al., 2018; Canedo et al., 2018);

2) the use of various information resources (e-libraries, exhibitions, expositions) presented on the Internet (Madge et al., 2009; Kalelioglu, 2017);

3) online learning development (Purarjomandlangrudi et al., 2016; Funes\&Mackness, 2018);

4) the spread of interactive teaching methods (Takala et al., 2016; Brecka\&Valentova, 2017; Mihailidis, 2018; Alifirov et al., 2018).

General trends make it possible to identify the functions of multimedia learning complexes:

1) informative, reflecting the inclusion in the content of educational material necessary educational, scientific, practical knowledge (Pugacheva et al., 2016);

2) transformative, providing translation of educational material in an interactive form and allowing the learning process to take place in extracurricular time (Lunev et al., 2014);

3) axiological, contributing to the formation of scientific and professional worldview among students (Lunev et al., 2014);

4) organizationally stimulating, providing effective leadership of the learning process (Ibragimov, 2016);

5) the function of self-education, which allows the use of a multimedia training complex as an autonomous information and methodological tool of learning (Ibragimov, 2016);

6) the function of health preservation, causing the study of educational material at a convenient pace (Aleksic\&Ivanovic, 2016).

The relevance of the study is due to the development of information and methodological tools of vocational education. Electronic publications are increasingly being used as system integrity of graphic, textual, digital, speech, music, video, photo and other information made on magnetic, optical media and also published on an electronic computer network (Gikas\& Grant, 2013; Aleksic\&Ivanovic, 2016; Chareen, 2018). Russia has a system of state standards that formulate state requirements for the quality of 
products, works and services of intersectoral importance. Since 1992, the state standard of the Russian Federation has the designation GOST. IT confirms that the products are tested and meets all safety requirements (Great Soviet Encyclopedia, 2018). Each GOST is established on the basis of the application of modern achievements of science, technology and practical experience, taking into account the latest editions of international standards or their projects. Information and educational tools are regulated by GOST 7.83-2001 (2018). The following information and methodological means are distinguished:

1) by the presence of a printed equivalent - an analogue of a printed edition, an independent edition;

2) by the nature of the main information - text, graphic, sound, multimedia edition, software product;

3) for its intended purpose - an official, scientific, popular science, regulatory, industrial and practical, educational, mass-political, reference, advertising, artistic publication;

4) by distribution technology - local, network, publication of the combined distribution;

5) by the nature of the interaction of the user and the electronic edition - deterministic, non-deterministic (interactive);

6) by periodicity - non-periodic, serial, periodic, ongoing, updated;

7) by structure - one / multi-volume edition, electronic series.

Thus, a multimedia training complex is an informational-methodical means of education, which is an educational, independent, updated, one-volume, interactive edition, in which information of various kinds (video lectures, documentary newsreels, special videos, audio materials etc.) is solving specific educational problems. As an information and methodological tool, multimedia learning complexes can be classified for various reasons. There are three types of multimedia-learning complexes, including several forms.

1. Educational and theoretical multimedia-learning complexes, which contain systematized scientific and theoretical knowledge, and determine the activities identified by the educational program for students to be assimilated in order to develop general cultural and professional competencies through integrated informational influence on students (Brecka\&Valentova, 2017).

This type includes the following forms:

a) a multimedia textbook that contains educational material defined by the framework of the educational program in order to systematically present the basic scientific and theoretical knowledge and their acquisition (Funes\&Mackness, 2018);

b) amultimedia tutorial, including a complex of scientific-theoretical information (texts, photo, audio, video materials) supplementing printed publications (Gikas\&Grant, 2013); 
c) multimedia lecture courses providing for the integration of text, graphics, audio and video information into a single information field (Kalelioglu, 2017);

d) multimedia lectures providing multi-variant, multilevel learning and a variety of test tasks, exercises, tests (Madge et al., 2009).

It was found that educational theoretical multimedia-learning complexes allow 1) to conduct training in the form of a dialogue, in which students learn educational material in the process of asking questions, making various judgments. This provides prompt feedback, effective training in self-management, self-monitoring and correction of educational activities; 2) strengthen individualization, as each student works at a different pace. A variety of options for interactive educational material management, the possibility of its non-linear viewing ensure the quality of learning, the development of visual figurative thinking; 3 ) to ensure the non-linearity of studying educational material and its constant updating by placing interactive web elements, hyperlinks, establishing hyperlinks with additional literature in electronic libraries or educational sites (Brilingaite et al., 2018).

2. Educational and practical multimedia-learning complexes that contain information of a scientific and practical and applied nature, organized according to certain criteria and described in an interactive form (Akeem et al., 2016).

This type includes the following forms:

a) multimedia workshops designed to fix up educational material and test of knowledge, skills, abilities, competencies (Dong \&Jong, 2013);

b) multimedia collections of tasks and exercises that promote the creative and active learning of educational material;

c) multimedia chrestomathies that contain specially selected normative legal acts, artistic, scientific works or excerpts from them, photographic, audio and video materials constituting the subject of educational material, as well as stimulating the thinking of the student, contributing to focusing on problematic and promising issues development of a specific science (Chareen, 2018).

Educational and practical multimedia-learning complexes provide 1) extracurricular work; 2) the activity nature of learning, the formation of students' methods of communication, thinking, actions; 3) integration of verbal and visual-sensual information, which contributes to the development of students' motivation: target ("I need to know this and be able to perform these tasks and exercises"); cognitive ("I get new knowledge and participate in the process of their formation"); praxeological ("I am satisfied with the acquisition of new knowledge and the process of studying educational material"); attitudinal ("it is interesting to me to study") (Dorca et al., 2016).

3. Educational and methodical multimedia-learning complexes that contain ordered educational material for self study of the academic discipline, topics and methods of various practical forms of fixing up knowledge, presented in an interactive form (Canedo et al., 2018). 
This type includes the following forms:

a) multimedia guidelines, including educational material for self-study by students and preparation for the test of knowledge (Means, 2018);

b) multimedia educational reference books, including brief information of a scientific or applied nature, intended for learning through conveniently located hyperlinks (Potter, 2018);

c) multimedia educational explanatory or terminological dictionaries, which are compiled for educational purposes, intended to expand and deepen knowledge in a particular academic discipline (Purarjomandlangrudi et al., 2016);

d) bibliographic reference books that contain an ordered set of bibliographic information on a specific problem and are designed to organize students' independent work on the study, assimilation and fixing up of educational material that has already been learned (Mihailidis, 2018).

It was found out that the educational and methodical multimedia-learning complexes ensure the development of 1) mental activity; 2) research skills; 3) interdisciplinary communication as a result of the use of modern information processing tools (Takala et al., 2016).

The educational material of a multimedia training complex is a system of knowledge, methods and experience of activity, emotional and value attitude to the subject of study. Knowledge includes terms, concepts, theories, facts, schemes, tables, illustrations. The methods of activity combine skills and abilities that can be 1) subject (exercises, tests, tasks), 2) organizational (note taking, bibliography, presentations, speeches). Experience is acquired through solving of problem tasks, developing of educational and industrial and socio-cultural projects, performing design work, etc. Forming an emotional-value relationship is carried out by including special tasks aimed at ethical assessment of objects, situations and processes in a multimedia-training complex. The purpose of the article is to develop practical recommendations on the selection and structuring of educational material for multimedia training complexes on occupational safety for future civil engineers.

According to the above information the problem of the research can be stated. The selection and structuring of training multimedia educational materials for university students can be considered a crucial part of the higher education bit unfortunately it may be not always provided properly. Thus, there are a list of measures that can help to partially solve the problem:

- design a research that'll show how selection and structuring of training multimedia educational materials for university students works in Russian universities;

- make a research analysis;

- use the research data form possible ways of problem solving. 


\section{Research Limitations}

The survey involved only Russian teachers and students (450 in total). This fact does not allow us to judge about the level of the idea of training multimedia educational materials for university students in other countries. In addition, all respondents are from Kazan State University of Architecture and Civil Engineering. This does not allow us to assess the situation in all educational institutions in general.

\section{METHOD}

The methodological basis of the study was general pedagogical and special principles for the selection and structuring of educational material. The selection of educational material is carried out on the basis of general pedagogical principles of competence, science and a special principle of relevance. The structuring of educational material is carried out on the basis of general pedagogical principles of integration, visibility, personalization and special principles of emergence and pertinence (see table 1).

Table 1

Principles for the Selection and Structuring of Educational Material of Multimedia Training Complex

\begin{tabular}{|c|c|c|c|}
\hline $\begin{array}{l}\text { Selection } \\
\text { structuring } \\
\text { educational } \\
\text { material }\end{array}$ & $\begin{array}{l}\text { and } \\
\text { of }\end{array}$ & General pedagogical principles & Special principles \\
\hline \multirow{2}{*}{$\begin{array}{l}\text { Selection of } \\
\text { educational } \\
\text { material }\end{array}$} & & $\begin{array}{l}\text { Competence, aimed at the formation of } \\
\text { competencies defined by the educational } \\
\text { standard, training in self-management, self- } \\
\text { control and correction of educational } \\
\text { activities }\end{array}$ & \multirow[t]{2}{*}{$\begin{array}{l}\text { Relevance, which determines the } \\
\text { actual, practice-oriented } \\
\text { orientation, non-linearity of } \\
\text { educational material studying and } \\
\text { its constant updating, meeting the } \\
\text { expectations of students }\end{array}$} \\
\hline & & $\begin{array}{l}\text { Scientific, that provides students with the } \\
\text { development of the skills and abilities of } \\
\text { research activities, contributing to the } \\
\text { concentration of attention on the problematic } \\
\text { and promising issues of development of a } \\
\text { particular science }\end{array}$ & \\
\hline \multirow{3}{*}{$\begin{array}{l}\text { Structuring } \\
\text { educational } \\
\text { material }\end{array}$} & \multirow[t]{3}{*}{ of } & $\begin{array}{l}\text { Integration, orienting to the establishment of } \\
\text { interdisciplinary connections, combining } \\
\text { verbal and visual-sensual information to } \\
\text { develop students' motivation, ways of } \\
\text { communication, thinking, actions }\end{array}$ & $\begin{array}{l}\text { Emergence, ensuring the } \\
\text { establishment of relationships } \\
\text { between components of the } \\
\text { educational material and its system } \\
\text { integrity }\end{array}$ \\
\hline & & $\begin{array}{l}\text { Visibility, causing the development of visual } \\
\text { thinking, mental activity, dialogical forms of } \\
\text { learning }\end{array}$ & \multirow{2}{*}{$\begin{array}{l}\text { Pertinencies, ensuring the } \\
\text { compliance of educational } \\
\text { material with the information } \\
\text { needs of students and its } \\
\text { interiorization,use of modern } \\
\text { information processing tools }\end{array}$} \\
\hline & & $\begin{array}{l}\text { Personalization, allowing to position the } \\
\text { student as a subject of the learning process by } \\
\text { identifying, recording and developing } \\
\text { individual abilities, improving the individual } \\
\text { style of thinking }\end{array}$ & \\
\hline
\end{tabular}

The set of principles of selection (competence, science and relevance) and structuring (integration, visibility, personalization, emergence, pertinence) of educational material 
allows to establish the relationship between its components (knowledge, ways and experience, emotional value attitude):

1) optimization of the selection of educational the material is enhanced on condition that it meets the information needs of students, taking into account their individual abilities and its developing (Kalelioglu, 2017);

2) improving the structure of educational material is achieved taking into account systemic integrity of its components (Aleksic\&Ivanovic, 2016);

3 ) the effectiveness of the formation of competencies increases, on condition of continuous updating of educational material, focusing on the needs of the regional labor market (Ivanov et al., 2016);

4) the efficiency of knowledge acquiring increases if it is relevant, using modern means of information processing (Terentyeva, 2017);

5) the effectiveness of the development of methods of activity increases under the condition of practice-oriented orientation (Lunev et al., 2016);

6) the importance of activity experience enhancing increases with the condition of the internalization of educational material, the conjugation with the socio-economic policy of the region (Pugacheva et al., 2016);

7) the effectiveness of the formation of emotional-value relationships increases under the condition of the development of figurative and visual thinking (Terentyeva, 2017);

8) the efficiency of educational material learning increases due to selection in accordance with the expectations of students and structuring, taking into account interdisciplinary connections (Potter, 2018).

\section{Research Tools}

In the process of research, theoretical (generalization, systematization) and sociological (observation, interview, questioning) methods were used. Experimental work on testing the effectiveness of methods for selecting and structuring educational material took place in three stages (ascertaining, shaping, controlling). The questionnaire included open and closed questions. The results of the survey were discussed in 11 focus groups of teachers, students, each of which included 9 people. The participants were personally invited to the focus groups who were not familiar with each other.

At the formative stage, multimedia training complexes on labor safety in construction were developed and implemented. At the control stage, the levels of learning of multimedia learning complexes by students were identified.

For the survey analysis the methodology of quantitative research was used. The analysis was made with the help of Microsoft Access. 


\section{Participants Selection Criterion}

450 people participated in the experimental work: 50 teachers, 400 students of the federal state budgetary educational institution of higher education "Kazan State University of Architecture and Civil Engineering" (Kazan, Russia). Were drawn up probabilistic samples of teachers, students.

The sample of teachers includes professors (average age 51 years) and associate professors (average age 36 years), who conduct training sessions in the disciplines of the professional cycle ("General electrical engineering and power supply", "Hydraulics, water supply and water disposal", "Heat engineering, heat and gas supply and ventilation", "Technological processes in construction") with students enrolled in major "Industrial and civil construction".

In the sample of students included students of 3-4 courses, studying on major "Industrial and civil construction". None of the teachers, students refused to participate in the experimental work. At the ascertaining stage, using the questionnaire, the attitude of teachers and students to multimedia-teaching complexes as an information and methodological tool of learning was clarified, and the criteria for educational material learning were determined.

\section{The Validity and Reliability of The Research}

The research can be considered valid since it has rather big number of participants of different ages, genders and sectors of employment. It allows to see the problem from different points of view and form some recommendations according to the results. However, the research can be widen for obtained more detailed information. The study can be also considered reliable since the statistical error is not more than $3 \%$. The core factors were tested for reliability. A reliability coefficient of 0.70 considered acceptable in social science researches.

\section{FINDINGS}

The main results of the study were the methods of selection and structuring of educational material. The methods are associated with the principles of selection and structuring of educational material. Accordingly, the selection of educational material is carried out by methods of conformity assessment, variability, adequacy. Structuring of educational material is carried out by the method of compatibility, smart-method, method of interactivity, virtualization, modularity. Consider the content of the methods.

The method of conformity assessment provides for the selection of educational material in accordance with the state educational standard, which approves the list of general cultural and professional competencies. For example, educational material was selected in the multimedia training complex on electrical safety and protective earthing devices of electrical installations, ensuring the formation of general cultural and professional competencies (see Table 2). 
Table 2

Learning Material of Multimedia Training Complex on Electrical Safety and Protective Grounding Devices of Electrical Installations, Ensuring the Formation of General Cultural and Professional Competencies

\begin{tabular}{ll}
\hline Educational material & General cultural competence \\
safety basics & $\begin{array}{l}\text { possession of a culture of } \\
\text { thinking, the ability to generalize, } \\
\text { analyze, perception of } \\
\text { information, setting goals and } \\
\text { choosing ways to achieve it; the } \\
\text { ability to find organizational and } \\
\text { managerial decisions in non- } \\
\text { standard situations and the } \\
\text { willingness to take responsibility } \\
\text { for them }\end{array}$ \\
&
\end{tabular}

\author{
out operations for the \\ installation of grounding \\ devices
}

knowledge of the rules and technology of

installation, tuning, testing and

commissioning of structures, engineering

systems and equipment of construction

sites, product samples produced by the company; possession of the methods of experimental verification of equipment and means of technological support; possession of methods for assessing the technical condition and residual life of construction objects, equipment

knowledge of the methodology for calculating the grounding

of electrical installations

Knowledge and experience

in the application of the

electrical design grounding

algorithm

the use of the basic laws of natural sciences in professional activities, the use of methods of mathematical analysis and modeling, theoretical and experimental research possession of methods for conducting engineering surveys, technology for designing parts and structures in accordance with the terms of reference using licensed applied calculation and graphic software packages

Knowledge of electrical installation rules

knowledge of the regulatory framework in the field of engineering surveys, the principles of designing buildings, structures, engineering systems and equipment, planning and building settlements

Knowledge of intersectoral rules on labor protection in the operation of electrical

installations production situations associated with violations of operations during use of the main provisions and methods of social, human and external social and professional tasks circuit of the grounding device possession of the main methods of protecting production personnel and the public from the possible consequences of accidents, catastrophes, natural disasters the ability to organize workplaces, their technical equipment, placement of technological equipment, monitoring compliance with technological discipline and environmental safety; knowledge of production organization and effective management of people's work

International Journal of Instruction, July $2019 \bullet$ Vol.12, No.3 
From table 2 it is clear that the training material provides for the formation of competencies of future civil engineers.

The method of variation focuses on the selection of different versions of educational material, based on scientific concepts. The variability method determines the formation of skills in research activities. Such skills include work with catalogs, archives, informational reviews; drawing up card files, abstracts, annotations, thematic extracts, flowcharts; execution of drawings, diagrams, graphs; creating presentations. For example, a multimedia training complex on electrical safety and protective grounding devices of electrical installations includes a typical technological map of the production of works on the installation of external and internal grounding. Such a map is used in the development of production projects, construction, other organizational and technological documentation, as well as familiarization of workers and engineeringtechnical workers with the rules of work (Sabirova, 2016). A typical technological map was developed taking into account 1) building and sanitary standards, 2) fundamental concepts, laws of physics, 3) methods of forming specified structures and properties of materials with maximum resource and energy saving, methods for evaluating their quality indicators, prospects for developing power supply systems for buildings, 4) basic provisions the theory and practice of calculating single-phase and three-phase electrical circuits, devices, 5) principles of operation of electrical machines and electrical equipment, 6) typical power supply schemes for building and construction objects, 7) fundamentals of electronics and electrical measurements. In the multimedia training complex on electrical safety and protective grounding devices of electrical installations, it is proposed to study the scientific and technical information, domestic and foreign experience in creating process charts for specific types of work and prepare a report in the prescribed form, as well as develop a process chart for specific types of work.

The method of adequacy provides a practice-oriented direction of educational material and its compliance with the expectations of students. For example, for a multimediatraining complex for the study of air dustiness, an educational material was selected, including, firstly, ways to combat dust in industrial premises. Students are encouraged to familiarize themselves with the hygienic requirements for the air of industrial premises; consider the classification of ventilation methods; determine the required air exchange; calculate the natural ventilation; to calculate the deflector. Secondly, the training material includes the method of studying dust in the air by the gravimetric method, which includes: determining the concentration of dust in the air using measuring equipment at a special installation, evaluating the results in accordance with sanitary standards and finding a class of working conditions.

If expectations are both an emotional state and a structural and operational education, then the educational material may correspond to the following students' expectations: cognitive (related to the perception of educational material); activity (related to skills, abilities, competences); subliminal (associated with motivational-targeted activities); emotionally evaluative (associated with a positive attitude to the educational material). It has been found that students have the following expectations: 
- cognitive - "I expect to gain knowledge in the field of safe use of work equipment", "I plan to gain knowledge and skills to ensure human safety at construction sites";

- activity - "learning will help me to acquire the skills to ensure safety in the performance of construction and installation works", "I want to learn how to create comfortable working conditions and prevent negative impacts", "waiting for knowledge in the field of health protection, practical methods and ways to protect myself, preserve health", "Additional knowledge, skills of calculating the degree of danger of certain factors in the workplace";

- subliminal - "I expect to receive knowledge that will help ensure security during the performance of official duties," "I would like to gain more practical skills in life," "I would like more practice, as the notes leave no trace in my memory";

- emotionally evaluative - "learn to treat in good faith the protection of others and myself in an enterprise", "waiting for knowledge that will help me in my future work, safety instructions, as well as knowledge of my rights, to avoid various unpleasant situations in the process of my work" , "Learn how to behave in this or that dangerous, emergency situation in order to protect your life, prevent an accident".

Compatibility method involves the establishment of interdisciplinary connections, the relationship with the production. For example, in the process of structuring educational material on the multimedia training complex "Assessment of object resistance to the impact of a nuclear explosion shock wave" were:

1) interdisciplinary interactions with disciplines are established:

a) humanitarian, social and economic cycle: knowledge of the foundations of the Russian legal system and legislation, including in construction, organization of judicial and other law enforcement and law enforcement agencies, legal and moral ethical standards in the field of professional activity; knowledge of teamwork technologies and the ability to apply them;

b) natural science and general technical cycle: knowledge of fundamental concepts, laws and theories of classical and modern physics; basic concepts of the physics of a nuclear explosion and the mechanics of its action; information about the damaging factors of a nuclear explosion;

c) professional cycle: design and evaluation of the stability of the object; assessment of the stability of the object to the impact of the explosion shock wave determination of excess pressure, causing the displacement of the machinery relative to the base.

2) interrelations with production were found for the purpose of organizing educational and industrial practices, participating in the development and implementation of research and production projects; implementation of the collection, processing, analysis and systematization of scientific and technical information on the topic (task); participation in bench and industrial tests of prototypes (batches) of designed products; drawing up reports (report sections) on the topic (stage, task). 
The smart method provides for hyperlinks to various presentations: 1) textual, including basic (theoretical and educational), additional (documentary textbook) and explanatory (notes, dictionaries, applications) texts; 2) demo, including pictures, drawings, schemes, diagrams, photos, videos, technological maps, posters, signs, means of analyzing production risks; 3) control, including questions, tasks, tests, exercises; 4) reference, including the introduction, table of contents; rubrication and selection; signal symbols; pointers; References and Internet resources. For example, the educational material of the multimedia educational complex "Safety in the Construction and Maintenance of Highways" includes: 1) theoretical-informative texts, documentary and textbook materials, notes, a dictionary, applications; 2) graphic posters on the organization of the place of work with the use of various construction equipment and conditions of work; 3 ) special exercises and tests for the implementation of automated knowledge control; 4) a list of references and Internet resources intended for independent study of educational material.

The method of interactivity provides a hypertext structure with multimedia applications, navigation system and control of various components: 1) diagnostic, allowing to reveal the individual abilities of the student; 2) subject, allowing to localize educational material for the construction of individual educational trajectories; 3) comparative, allowing to compare the initial and current levels of training for setting tasks adequate to the immediate development prospects, increasing the efficiency of learning material mastering. For example, a multimedia workshop on occupational safety in construction provides for project activities of students. Students are invited to complete the project individually, in a couple or small group (4-6 people). The result of the project activity may be presentations, posters (campaigning, informational), technological maps, charts, instructions, videos on occupational safety. For the effectiveness of project activities, students can recommend the following sequence of actions: a) determine the topic, the number of performers, the goal and objectives of the project; b) identify potential sources of information necessary to achieve the goal; c) distribute tasks among the performers for their implementation and execution; d) conduct an interim discussion of the results obtained between the project implementers; e) draw up a project and prepare its presentation; f) obtain an opinion from the external expertise of the project on the following criteria: the relevance of the project topic; correctness of the information used; the necessity and sufficiency of the results obtained; esthetics and visibility of the project.

The virtualization method allows you to combine the components of educational material, to establish relationships between them: 1) the efficiency of mastering educational material is achieved subject to the systemic integrity of interdisciplinary interactions, the relationship with production; 2) the quality level of mastering the educational material is increased provided it is localized for building individual educational trajectories; 3 ) the formation of common cultural competencies is achieved subject to the inclusion of special tasks aimed at the ethical assessment of labor protection at work; 4) the interiorization of educational material will be successful provided it is used in extracurricular work (meetings with representatives of Russian and foreign companies, master classes of experts and specialists). For example, a multimedia 
collection of tasks contains a set of test tasks, in each of which it is proposed to choose the correct version of the safe method of conducting work in various production situations. Each answer is accompanied by a visual illustration and the student is invited to choose the one that does not contain an error. The collection of tasks is designed in such a way that allows you to work with it, both on the local computer and remotely using the Internet. There are several advantages of using multimedia collections of tasks: a) unlimited work time, determined by the student himself; b) extracurricular work; c) the possibility of modeling various relationships and conditions of real life.

Another example would be a multimedia album, including a series of graphic posters on industrial and civil construction. This album allowed us to present a number of virtual construction sites and a variety of production situations faced by engineering and technical personnel (see Figure 1).

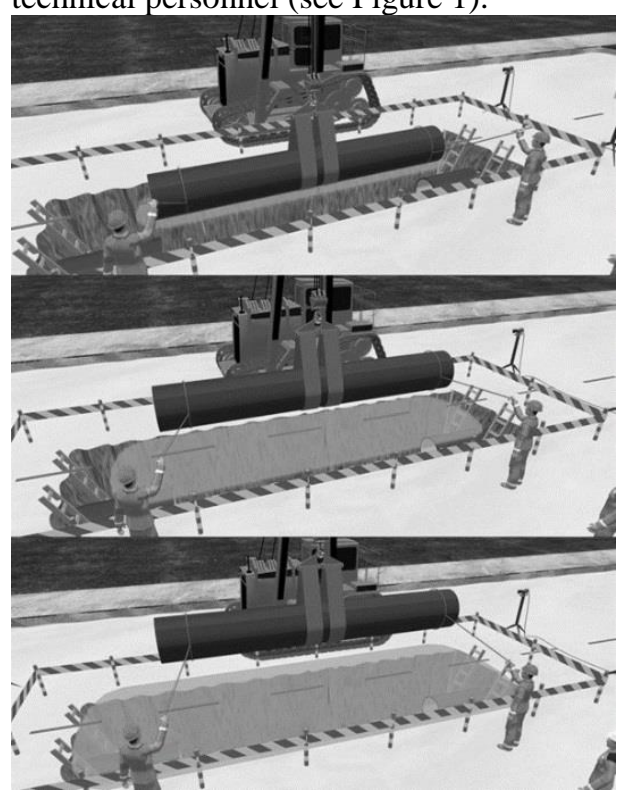

Figure 1

Changing the Zone of Possible Load Drop Depending on the Height of the Boom Lift

From Figure 1 it can be seen that the album consists of three-dimensional spatial images of the construction site and its elements, areas of production of certain types of work. On the posters included in the album, specially designated places regulate the selectivity of attention due to the preferential display of individual objects, contributing to the disclosure of the most characteristic properties and parameters that affect the performance of work in compliance with safety requirements. The use of the album: a) led to a fairly quick entry of students into the learning process and the inclusion of figurative thinking in the process of learning the content; b) allowed students to familiarize themselves with different production situations and to form skills and abilities that ensure safe and trouble-free work; c) made it possible for students to form 
associations reflecting objective connections and relationships between production processes and individual operations; the cause and effect of creating dangerous and emergency situations that can lead to accidents and injuries; d) provided information support for training.

The modularity method allows structuring educational material according to modules focused on: 1) types of professional activity (design and survey, production and technological, production and management, experimental research, installation and commissioning, operational); 2) information needs of students (knowledge of the technology of safe production of various types of work, safe operation of construction machines and equipment; possession of modern software packages for calculating and designing the safety of construction objects and methods of their construction, modern instruments used to measure parameters and assess the degree of hazard and harm production factors. An example would be a multimedia reader, including regulations, research papers, photos, audio and video materials. The use of the reader makes it possible to: a) establish links between activities; b) involve students in the discussion of educational, production and emotional-moral situations; c) provide an opportunity for each student to study using operational, regular self-assessment and self-control.

Experimental work on testing the effectiveness of methods for selecting and structuring educational material took place in three stages (ascertaining, shaping, controlling). At the ascertaining stage, with the help of questionnaires, the attitude of 50 teachers and 400 students to multimedia-teaching complexes as an information and methodological tool was found.

The questioning of students showed that the majority prefer to work with multimedia teaching aids (89\%), allowing them to choose the level and pace of study of educational material $(81 \%)$, to work independently, outside the audience (87\%). As the main requirements for a multimedia learning complex, students put forward: structuring educational material based on three-dimensional modeling and animation programs (92\%), including legal acts (72\%), photo, audio, video materials, posters (91\%).

Teachers prefer to use multimedia tools for dialogization (63\%) and personalization (64\%) of the educational process, a combination of classroom activities with independent work of students $(71 \%)$. The main requirements for the multimedia training complex include: compliance of the content with the requirements of state educational standards (91\%), international, national, and industry standards of occupational safety (89\%); modular structuring of educational material $(86 \%)$; the inclusion of test materials (92\%), competence-oriented tasks (94\%).

11 focus groups were created from the teachers and students (each included 5 teachers and 4 students), which defined the criteria for the development of educational material: 1) knowledgeable (they know the regulatory legal acts that ensure labor safety, the basics of occupational health, industrial sanitation, technical aesthetics, safety, aware of the dangers of occupational exposure (noise, chemicals, vibration, heat, stress, infectious diseases); 2) activity (able to identify hazards related to working conditions in the workplace; to ensure the safety of workplaces; to minimize the risk of exposure to 
adverse conditions to an acceptable level; to organize legal, socio-economic, technical, sanitary and hygienic, therapeutic and preventive, rehabilitation measures for labor safety); 3) competence-based (own methods of selection of construction materials that provide the required indicators of reliability, safety, efficiency and efficiency of facilities; methods of monitoring occupational safety; methods of determining the priority of hazards and developing strategies to improve labor safety).

At the formative stage, a multimedia training complex on occupational safety in construction was developed and introduced (see Figure 2).

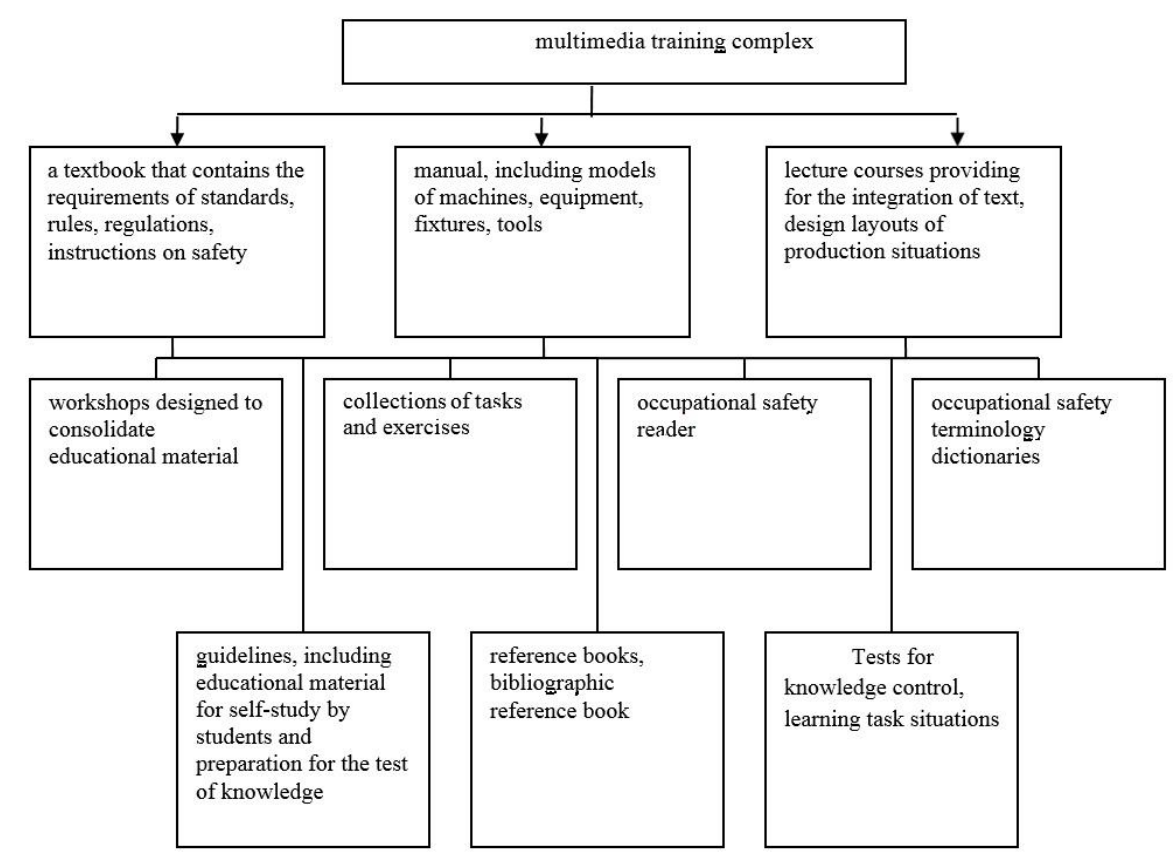

Figure 2

Multimedia Training Complex on Occupational Safety

From figure 2 it can be seen that the complex is characterized by polystructurality. Each component of the structure includes three-dimensional posters (see Figure 3). 


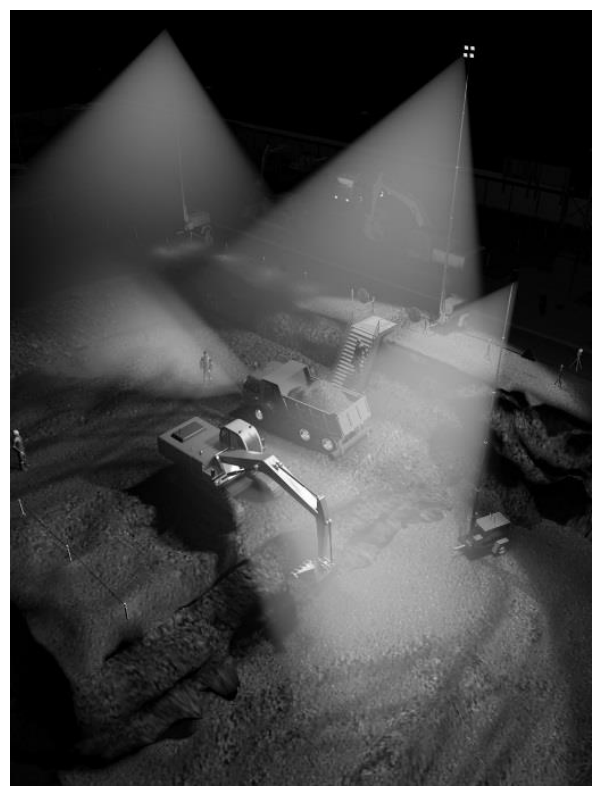

Figure 3

Poster "Artificial Lighting of the Construction Site"

From Figure 3 it can be seen that the three-dimensional posters simulated production situations, equipment and mechanisms, various conditions for the conduct of work and specialists involved in the production process. Creation and implementation of threedimensional posters allows you to "popularize" learning. "Popular" learning is based on the philosophy of the Brazilian teacher Paulo Freire (2000) and allows you to enhance the learning activities of students. The essence of "popular" or "stimulating" learning is that, in the process of studying educational material, students consider specific issues and situations that occur in production. And this involves a dialogue between the teacher and the trainees.

At the control stage of experimental work, the levels of mastering the educational material of a multimedia training complex by students were revealed. Based on the selected criteria, students were asked to answer several questions and complete assignments. Answers to questions and assignments were evaluated on a 5-point scale. The results obtained are presented in table 3 . 
Table 3

Dynamics of the Learning of Educational Material by Students on Ascertaining and Control Stages of Experimental Work (average score)

\begin{tabular}{|c|c|c|}
\hline \multirow[b]{2}{*}{ Criteria and indicators } & \multicolumn{2}{|l|}{ stages } \\
\hline & ascertaining & control \\
\hline \multicolumn{3}{|l|}{ Knowledge criterion $(\mathrm{K})$} \\
\hline 1. know the regulatory legal acts ensuring labor safety & 2,5 & 4,6 \\
\hline $\begin{array}{l}\text { 2. know the basics of occupational health, industrial sanitation, technical } \\
\text { aesthetics, safety }\end{array}$ & 2,6 & 4,3 \\
\hline $\begin{array}{l}\text { 3. Can describe the dangers of occupational exposure (noise, chemicals, vibration, } \\
\text { heat) }\end{array}$ & 2,8 & 4,8 \\
\hline 4. Can describe the dangers of industrial stress. & 2,7 & 4,9 \\
\hline 5. Know international and industry safety standards & 3 & 4,8 \\
\hline \multicolumn{3}{|l|}{ activity criterion $(\mathrm{A})$} \\
\hline 6. able to identify hazards related to working conditions in the workplace & 2,9 & 4,8 \\
\hline 7. able to ensure the safety of jobs & 2,8 & 4,9 \\
\hline 8. know how to organize legal, socio-economic, technical measures for labor safety & 2,9 & 5 \\
\hline $\begin{array}{l}\text { 9. know how to organize sanitary and hygienic, treatment-and-prophylactic, } \\
\text { rehabilitation measures for labor safety }\end{array}$ & 3,1 & 4,9 \\
\hline $\begin{array}{l}\text { 10. able to minimize the risk of exposure to adverse conditions to an acceptable } \\
\text { level. }\end{array}$ & 2,3 & 4,8 \\
\hline \multicolumn{3}{|l|}{ competence criterion $(\mathrm{C})$} \\
\hline $\begin{array}{l}\text { 11. Own methods of selection of construction materials that provide the required } \\
\text { indicators of reliability, safety of structures }\end{array}$ & 2,9 & 4,8 \\
\hline $\begin{array}{l}\text { 12. Own methods of selection of construction materials that provide the required } \\
\text { indicators of the efficiency of buildings }\end{array}$ & 2,4 & 4,8 \\
\hline $\begin{array}{l}\text { 13. Own methods of selection of construction materials that provide the required } \\
\text { performance indicators of structures }\end{array}$ & 2,6 & 4,9 \\
\hline 14. Own methods of safety control & 2,7 & 5 \\
\hline $\begin{array}{l}\text { 15. Own methods of prioritizing hazards and developing strategies to improve } \\
\text { safety }\end{array}$ & 2,3 & 4,9 \\
\hline
\end{tabular}

From table 3 it can be seen that the training of students with the help of a multimedia training complex, the training material for which was selected and structured on the basis of the methods we have identified, gives a positive dynamic. To identify the levels of development of educational material at the establishing and control stages of experimental work, we determined the value (W) as the sum of the values for each criterion: $\mathrm{W}=\mathrm{VK}+\mathrm{VA}+\mathrm{VC}$.

The values for each criterion were calculated by the formula: $\mathrm{V}=\Sigma \mathrm{qi} / \mathrm{n}$, where qi is the average score obtained for the indicator, $\mathrm{n}$ is the number of criteria indicators. We conditionally consider values (W) from 0 to 5 as the knowledge level of the formation of skills. Values from 6 to 10 - activity level. Values from 11 to 15 - competency level. Levels characteristics is as follows. Competence level - students understand the essence of occupational safety, know how to identify hazards and strategies to improve occupational safety, and organize work safety measures. Activity level - students have an understanding of occupational safety, but do not have information about international labor safety standards, know how to identify hazards and ensure safety of workplaces, have control methods of occupational safety, but partly formed the ability to prioritize hazards and develop strategies to improve occupational safety. Knowledge level students understand the essence of occupational safety, they know international and 
industry standards for occupational safety, but the skills to ensure occupational safety are partially formed.

\section{DISCUSSION}

If the general trends reflect the strategy for the development of education, then the national trends reflect the methodological tactics of learning: the personalization of learning in European countries; introducing smart education in Asian countries; the formation of general cultural and professional competences, approved by educational standards in Russia.

In Europe, the multimedia learning complex is seen as an effective means of personalizing learning and "learning life". Personalization of training involves not only taking into account the individual characteristics of each student, but also the development of subject-subject relations, with the aim of including students in the design process and the organization of personal and professional development. In practice, students and teachers have access to educational material at any time and any place with Internet access. This stimulates the creation by teachers and students of their own Web pages, the publication of online journals, electronic encyclopedias, the organization of forums and conferences. "Learning life" means changing attitudes towards digital technologies that are increasingly penetrating everyday life: digital literacy and social attitudes can converge in a new understanding of digital opportunities (Means, 2018).

In Asia (China, South Korea, Malaysia, Hong Kong, Macau), smart education is being actively implemented to integrate the learning process into everyday life and educate an information adapted student who is able to orient in information flows, e-learning, and work with the latest technologies (Dong \&Jong, 2013). The concept of smart was first mentioned in the context of aerospace technology, the creation of which was supported by the transition to new materials, the use of new material properties, advances in electronics and information technology. Thus, "smart" is a property of a system or process, which manifests itself in interaction with the environment, and gives the system or process the ability to immediately respond to changes in the external environment; adaptation to transforming conditions; self-development and self-control; effective achievement of results. In practice, the concept of smart education provides student access to educational resources related to common tasks and operating on the basis of a single software platform. The implementation of the concept includes the organization of interactive learning based on computer audiences, distance lectures and teacher consultations; the introduction of electronic textbooks; the use of multimedia tools for presenting educational material and various information resources presented on the Internet; creation of a unified educational environment accessible through various types of electronic devices, including computers, tablets, smartphones and smart-TV; application of the opportunities provided by cloud services, which allows minimizing the resources involved and simplifying access to various educational products. Various non-profit organizations are involved in the development of smart education. Certified educational programs on academic disciplines are being developed and implemented; special resources for teachers, including 3D modeling technology; technologies for the 
use of cloud services for distance and corporate training, refresher courses (Akeem et al., 2016). In Asian countries, multimedia learning complexes are also aimed at implementing an integrative function, which allows selecting and structuring educational material for an adequate integrated perception.

In Russia, the selection and structuring of educational material for a multimedia-learning complex is carried out in the context of the formation of general cultural and professional competences, approved by educational standards in each area of vocational education. This leads to the creation and implementation in practice of multimedia training complexes of various types and kinds. For example, a multimedia textbook on the process of hydration and structure formation of modified self-compacting concrete, consisting of four CDs and a brochure (Ibragimov et al., 2017). The authors selected and compiled educational material taking into account the peculiarities of its presentation in visual form with the accompanying audio sequence. The combination of audio and video materials makes it possible to increase the efficiency of course learning due to the complex effect of visual and auditory information on students. The inclusion of interactive elements in the textbook further stimulates the cognitive interest of students. Learning with the help of a multimedia textbook is possible both in a computerized classroom and at home. It is also possible to adapt the textbook for use in distance learning systems. Multimedia textbooks allow teaching in the form of a dialogue, in which students acquire knowledge in the process of asking questions, making different judgments, etc.

Another example would be a multimedia lecture on reducing energy costs associated with the production of fiber-cement panels for construction. The lecture contains textual material, graphic illustrations. Using a three-dimensional modeling program, models for the production of fiber-cement panels were created (Mihailidis, 2018). It was found that multimedia lectures can be used both in the study of a new topic and in a combined lesson, when a test of students' knowledge of the previous material is accompanied by the presentation of a new material. The advantage of a multimedia lecture is that it has a clear composition, it involves a slender and demonstrative monologue presentation. Multimedia lectures allow for a relatively short time to give a large amount of educational material, and thanks to the systematic presentation students can create a holistic view of the process or object under study. The inclusion of graphic illustrations in a multimedia lecture provokes an active and emotional response from the audience, supports its interest in the content, and contributes to the formation of beliefs.

The study of national trends in the process of selecting and structuring educational material for multimedia learning complexes is of great importance, since the training tactics used by different countries can be interesting and useful.

\section{CONCLUSION}

Practical recommendations on the selection and structuring of educational material for multimedia training complexes on occupational safety for future civil engineers are as follows. First, the effectiveness of the selection and structuring of educational material for multimedia-learning complexes will increase under the condition of studying 
national trends. This will allow to compare own methods of selection and structuring of educational material with the experience of others and thereby evaluate their feasibility and implementation risks. Secondly, the effectiveness of the selection and structuring of educational material for multimedia learning complexes increases, provided that principles are defined, the methodological significance of which is to adjust and synthesize sustainable knowledge in the process of understanding and transforming reality. The principles determine the requirements for the methods of selection and structuring of educational material, ensure their validity, updating. Third, the optimization of the selection and structuring of educational material for multimedialearning complexes is enhanced, provided the methods are improved, as tools for establishing relationships between the educational material and subjects of training. This contributes to the promotion of learning, the conscious mastering of educational material. The results obtained allow to outline the prospects for further research of this problem, which are associated with the development of methods for the organization of a vocational-oriented, virtual-educational environment. In the practical purpose the results of this study can be used for analyzing and improving universities methods in multimedia structuring by making students' surveys. After their results the right methods or their combinations for every focus group can be selected. Before forming particular methods of selection and structuring multimedia materials for a certain university it is necessary to understand the needs of its students. For this purpose, universities can organize surveys that will show which types of multimedia structuring will be good for a certain organization. Also, the analysis of the university's current multimedia structuring can be conducted to see if it needs any changes. After analyzing surveys and the structure of the university its authorities can choose the way of structuring that are more suitable for them. The methods can be based on the survey's results, the age of the students, their specialty and other aspects. It will help to improve multimedia structuring methods and lead to the better results in education. Since its always impossible to give proper and whole education basing on only one multimedia structuring method universities can combine them according to the need of the students

\section{REFERENCES}

Akeem, P., Quang, T. L., \& Chan, S. P. (2016). Framework for integrating safety into construction methods education through interactive virtual reality. Journal of Professional Issues in Engineering Education and Practice, 142(2), 713-725.

Aleksic, V., \& Ivanovic, M. (2016). Introductory programming subject in European higher education. Informatics in Education, 15(2), 163-182.

Alifirov, A. I., Mikhaylova, I. V., Makhov, A. S., \& Belov, M. S. (2018). Introducing chess education in Russian school system: Theoretical and practical aspects. Theory and Practice of Physical Culture 5.

Brecka, P., \& Valentova, M. (2017). 'Model of the students' key competences development through interactive whiteboard in the subject of technology. Informatics in Education, 16(1), 25-38. 
Brilingaite, A., Bukauskas, L., \& Juskeviciene, A. (2018). Competency assessment in problem-based learning projects of information technologies students. Informatics in Education, 17(1), 21-44.

Canedo, E. D., Santos, G.A., \& Leite, L. L. (2018). An assessment of the teachinglearning methodologies used in the introductory programming courses at a Brazilian university. Informatics in Education, 17(1), 45-59.

Chareen, S. (2018). Video production in content-area pedagogy: a scoping study of the research literature. Learning, Media and Technology, 43(3), 294-306.

Dong, I., \& Jong, L. (2013). Mission-type education programs with smart device facilitating LBS. International Journal of Multimedia and Ubiquitous Engineering, $8(2), 81-88$.

Dorca, F. A., Araujo, R. D., de Carvalho, V. C., Resende, D. T., \& Cattelan, R. G. (2016). An automatic and dynamic approach for personalized recommendation of learning objects considering students learning styles: An experimental analysis. Informatics in Education, 15(2), 45-62.

Funes, M., \& Mackness, J. (2018). When inclusion excludes: a counter narrative of open online education. Learning, Media and Technology, 43(2), 119-138.

Gikas, J., \& Grant, M. (2013). Mobile computing devices in higher education: Student perspectives on learning with cellphones, smartphones \& social media. The Internet and Higher Education, 19, 18-26.

GOST 7.83-2001. http://www.infosait.ru/norma_doc/9/9935/index.htm

Great Soviet Encyclopedia. $\quad$ Retrieved from https://dic.academic.ru/dic.nsf/bse/76883/\%D0\%93\%D0\%9E\%D0\%A1\%D0\%A2

Ibragimov, R. (2016). The influence of binder modification by means of the superplasticizer and mechanical activation on the mechanical properties of the highdensity concrete. ZKG International, 06,34-39.

Ivanov, V. G., Barabanova, S. V., Shagieva, R. V., Chikisheva, N. M., Lunev, A. N., Volkova, N. V., Nabiullina, K. R., \& Spirina, E. V. (2016). The essence and content of state regulation of services development in conditions of increasing autonomy of federal state entities. International Review of Management and Marketing, 6(2S), 149-154.

Kalelioglu, F. (2017). Using facebook as a learning management system: Experiences of pre-service teachers. Informatics in Education, 16(1), 83-101.

Lunev, A. N., Pugacheva, N. B., \& Stukolova, L. Z. (2014). Development strategies for professional educational services under the increasing autonomy of territories within the federal state. Actual Problems of Economics, 160(1), 215-220.

Lunev, A. N., Safin, R. S., Korchagin, E. A., Sharafutdinov, D. K., Suchkova, T. V., Kurzaeva, L. V., Nikishina, S. R., \& Kuznetsova, N. A. (2016). The mechanism of 
industrial educational clusters creation as managerial entities of vocational education. International Review of Management and Marketing, 6(2S), 166-171.

Madge, C., Meek, J., Wellens, J., \& Hooley, T. (2009). Facebook, social integration and informal learning at university: 'It is more for socializing and talking to friends about work than for actually doing work'. Learning, Media and Technology, 34(2), 41-155.

Means, A. (2018). Platform learning and on-demand labor: sociotechnical projections on the future of education and work. Learning, Media and Technology, 43(3), 326-338.

Mihailidis, P. (2018). Civic media literacies: Re-imagining engagement for civic intentionality. Learning, Media and Technology, 43(2), 152-164.

Potter, J. (2018). Problematizing learning in the age of data 'acquisition': issues in research, teaching and learning with digital media and technology. Learning, Media and Technology, 43(2), 117-118.

Pugacheva, A. S., Filippova, V. P., Kon, A. Y., Dorzhieva, L. B., Silchenok, I. S., Pugacheva, N. B., Lunev, A. N., \& Mustafina, A. A. (2016). Market regulators of service spheres innovative development as a tool of regional socio-economic policy. International Review of Management and Marketing, 6(2S), 294-300.

Purarjomandlangrudi, A., Chen, D., \& Nguyen, A. (2016). Investigating the drivers of student interaction and engagement in online courses: A study of state-of-the-art. Informatics in Education, 15(2), 269-286.

Sabirova, F. M. (2016). Study of the contribution of Nobel Prize winners to the development of atomic and nuclear physics in pedagogical universities. European Journal of Science and Theology, 12(1), 69-80.

Takala, T. M., Malmi, L., Pugliese, R., \& Takala, T. (2016). Empowering students to create better virtual reality applications: A longitudinal study of a VR capstone course. Informatics in Education, 15(2), 287-317.

Terentyeva, I. V., Pugacheva, N. B., Lunev, A. N., Korshunova, O. V., \& Selivanova, O. G. (2017). Management of the formation of general cultural competence of the university students. Modern Journal of Language Teaching Methods, 7(6), 11-20. 